\title{
Case Files of the Emory University Medical Toxicology Fellowship: Inhalational Mercury Toxicity from a Traditional Vietnamese Product
}

\author{
Soumya L. Pandalai • Brent W. Morgan
}

Published online: 10 November 2011

(C) American College of Medical Toxicology (outside the USA) 2011

Keywords Mercury - Inhalation · Complementary therapies $\cdot$ Herbal product

\section{Case Presentation}

A 41-year-old woman attempted to treat her sinus congestion with a complementary and alternative medicine (CAM) product consisting of dime-size white pellets originally purchased in Vietnam by a family member who brought it with her to the USA. The remedy was obtained from one of her relatives who stated that treatment with these pellets had alleviated similar symptoms of other persons from her hometown in Vietnam. The patient was advised to heat the pellets on an electric stove for 2-3 days at various times, and inhale the fumes that were produced. After using the product for 2 days, she developed generalized malaise, dry skin, and poor appetite. She was later informed by a family member in Vietnam that the remedy may contain mercury and lead. She presented to her primary care clinic for metal testing, where initial total blood mercury (organic plus

Portions of this manuscript were previously presented in abstract form at the North American Congress of Clinical Toxicology, Denver, CO, USA, Oct. 7-12, 2010.

S. L. Pandalai

CDC Atlanta,

Atlanta, Georgia, USA

S. L. Pandalai $(\bowtie) \cdot$ B. W. Morgan

Emory University Medical Toxicology Fellowship,

Atlanta, Georgia, USA

e-mail: slpandalai@gmail.com inorganic) and total blood lead concentrations were found to be $409 \mu \mathrm{g} / \mathrm{L}$ (normal, $\leq 10 \mu \mathrm{g} / \mathrm{L}$ ) and $1 \mu \mathrm{g} / \mathrm{L}$ (normal, $<10 \mu \mathrm{g} / \mathrm{L}$ ), respectively. Her physician advised her to discontinue this treatment and was subsequently referred to the authors' toxicology clinic.

The patient's initial evaluation in our toxicology clinic was approximately 4 weeks after her initial exposure to the CAM product, and she continued to describe overall malaise and dry skin. She also complained of depressed mood and poor appetite. On physical examination, the patient was in no distress and her vital signs included a temperature of $36.9^{\circ} \mathrm{C}$, heart rate of 109 beats per minute, blood pressure of 125/81 mmHg, and respiratory rate of 18 breaths per minute. Her oral exam showed mild erythema of the tongue, but no evidence of gingivostomatitis (which may occur with mercury toxicity). Her mini-mental status examination including orientation to person, place, time, attention, immediate and delayed recall, naming, repetition, reading, writing and copying was normal. She was able to follow a three-stage command with no difficulty. No other abnormalities were noted on the remainder of her neurological examination, which included gross cranial nerve testing, deep tendon reflexes, muscle strength, gait, cerebellar function, and sensation to pin-prick testing. Her skin exam was notable for generalized dryness of the extremities.

A complete blood count showed a white blood cell count of $6.8 \mathrm{k} / \mu \mathrm{L}$ (normal, $4-10.5 \mathrm{k} / \mu \mathrm{L}$ ), hemoglobin of $14.4 \mathrm{~g} / \mathrm{dL}$ (normal, $12-15 \mathrm{~g} / \mathrm{dL}$ ), a hematocrit of $44.5 \%$ (normal, $36-46 \%$ ), and a platelet count of $255 \mathrm{k} / \mu \mathrm{L}$ (normal, $150-400 \mathrm{k} / \mu \mathrm{L})$. A complete metabolic panel showed a sodium of $137 \mathrm{mEq} / \mathrm{L}$ (normal, 135-145 $\mathrm{mEq} / \mathrm{L}$ ), potassium of 4.2 (normal, $3.5-5.3 \mathrm{mEq} / \mathrm{L}$ ), chloride of $104 \mathrm{mEq} / \mathrm{L}$ (normal, 96-112 $\mathrm{mEq} / \mathrm{L}$ ), blood urea 
nitrogen of $14 \mathrm{mg} / \mathrm{dL}$ (normal, 6-23 $\mathrm{mg} / \mathrm{dL}$ ), and creatinine $0.71 \mathrm{mg} / \mathrm{dL}$ (normal, $0.4-1.2 \mathrm{mg} / \mathrm{dL}$ ). Liver enzymes were reported as alanine aminotransferase (ALT) $15 \mathrm{U} / \mathrm{L}$ (normal, 0-37 U/L) and aspartate aminotransferase (AST) $12 \mathrm{U} / \mathrm{L}$ (normal, 0-35 U/L). Finally, a total blood venous lead concentration was $1.0 \mu \mathrm{g} / \mathrm{dl}$ (normal, $<10 \mu \mathrm{g} / \mathrm{dL}$ ). Recommendations were made at this visit for repeat mercury testing in our laboratory. While awaiting results, the patient was empirically started on a 20-day chelation regimen with oral 2,3-dimercaptosuccinic acid (DMSA or succimer), $400 \mathrm{mg}$ by mouth three times a day for 5 days followed by $400 \mathrm{mg}$ by mouth twice daily for 2 weeks. She was advised to not use the product and was discharged home. Laboratory results returned after 1 week revealing a total blood mercury concentration of $61 \mu \mathrm{g} / \mathrm{L}$ and a 24-h urine mercury concentration of $497 \mu \mathrm{g} / \mathrm{g}$ creatinine (normal, $0-10 \mu \mathrm{g} / \mathrm{g}$ creatinine). The patient was notified of these results and advised to continue the full course of chelation regimen with follow-up in 4 weeks.

\section{What Are the Three Different Forms of Mercury?}

Mercury exists in three different forms, including elemental, inorganic, and organic. These forms vary in their physical, chemical, and kinetic properties. Clinical manifestations of each form in toxicity also differ. Elemental mercury, or hydrargyrum, is represented by the symbol $\mathrm{Hg}$ and is classified as a transition metal with atomic number 80. It is also known as metallic mercury and exists as a silvery nonflammable liquid at standard temperature and pressure. Elemental mercury, or "quicksilver", evaporates slowly even at standard temperature, but when heated releases even more vapor, which can be extremely toxic when inhaled [1]. Liquid mercury is poorly absorbed after ingestion; hence, inhalation is the most common route of exposure that leads to poisoning. Acute inhalational exposures to elemental mercury predominantly occur in three scenarios: occupational settings involving industrial accidents, accidents within the home, and in association with attempts to remove precious metals such as gold from mercury amalgams [2]. Vapors released by elemental mercury are rapidly absorbed by the lungs and can be irritating to the mucous membranes and pulmonary system. Due to its high lipophilicity, approximately $80 \%$ of inhaled elemental mercury vapor is absorbed by the alveoli. It then enters the systemic circulation where it is rapidly oxidized to mercurous $\left(\mathrm{Hg}^{+1}\right)$ and mercuric $\left(\mathrm{Hg}^{+2}\right)$ cations which distribute throughout the body [3]. This enzymatic reaction occurs within the red blood cell by the catalase-hydrogen peroxidase pathway and results in accumulation of the divalent cations within various cells [4]. In particular, these cations accumulate in the central nervous system (CNS) after penetration across the blood-brain barrier (BBB). Monovalent mercurous $\left(\mathrm{Hg}^{+1}\right)$ and divalent mercuric $\left(\mathrm{Hg}^{+2}\right)$ cations are less lipophilic than elemental mercury and once inside the CNS cannot cross over the BBB again. For this reason, the CNS is particularly susceptible to toxicity following elemental mercury exposure as mercurous and mercuric cations are essentially "trapped" in neuronal tissue and can accumulate with resulting neurotoxicity. In addition, mercurous mercury is a less soluble form than mercuric mercury and the production of insoluble compounds like mercurous sulfide and mercurous selenide are also thought to contribute to mercury accumulation in the CNS with resulting neurological damage [5].

Inorganic mercury compounds usually exist as salts, white powders or crystals. Ingestion is the most common route of exposure for inorganic mercury toxicity. These compounds, such as mercuric chloride, can be extremely corrosive to the gastrointestinal (GI) tract even though only $10-40 \%$ of a dose is absorbed across the GI mucosa [6]. Dermal absorption of inorganic mercury containing creams can occur depending on the concentration of mercury and the ion to which it is bound.

Organic mercury consists of compounds containing carbon molecules such as aryl, short-chain alkyl, and long- chain alkyl forms. Methylmercury is the prototypical short-chain alkyl mercury and one of the more common forms found in the environment. Phenylmercury is an aryl compound whose carbon-mercury bond is more labile than methylmercury. Upon absorption from the GI tract, phenylmercury converts into inorganic mercury and ultimately follows the kinetics and toxicity pattern of inorganic mercury salts.

What is Currently Known about the Heavy Metal Content and Exposure from the Use of CAM Products from around the World?

The National Center of Complementary and Alternative Medicine define CAM as a group of diverse medical and healthcare systems, practices, and products that are not generally considered part of conventional medicine. The available literature regarding metal content of CAM products specifically from Vietnam is scarce; however, limited data collected from other Southeast Asian countries where similar products are used and available are revealing [7-9]. These data suggest that heavy metals like mercury may be found in CAM products as a result of both unintentional contamination and intentional addition for purported benefit. For example, Ayurvedic medicine is an ancient Indian medical practice which uses alternative medicines that combine herbs, minerals, and metals in various proportions [7]. In a 2004 study of CAM products manufactured in India, the three most commonly detected 
metals were lead, mercury, and arsenic [8]. Similarly, a study from 2008 examining the heavy metal content of Ayurvedic products available on the internet suggested that $20.7 \%$ of the products analyzed had some detectable quantity of metal and the prevalence of metals in USmanufactured CAMs was only slightly higher than CAMs manufactured in India (21.7\% versus 19.5\%) [9]. Metal content in these products was further analyzed using X-ray fluorescence spectroscopy and one product contained $20,800 \mu \mathrm{g}$ of mercury per gram of product [9]. The mercury content in these products, if ingested, could result in daily intake amounts exceeding currently published regulatory standards, e.g., for mercury $30 \mu \mathrm{g} /$ day [10]. An examination of CAM products used in Ayurvedic practices suggests that conversion of trace metals contained in these products to less toxic mixed-oxides may explain the lack of generalized health effects seen in users [11]. In addition, a unique form of Ayurveda, known as Rasa Shastra, consists of the intentional mixing of herbs, metals, minerals, and gems in order to detoxify the body and alleviate various conditions [12].

Many world civilizations have historically considered mercury to contain healing and curative properties. Therefore, it is not surprising that ancient cultures of Southeast Asia may utilize this element in the manufacturing of medicinal products. Although it is not known whether specific CAM products used in the Ayurvedic practices of India are also used in other countries such as China and Vietnam, they are thought to be similar and derived from shared cultural practices. These practices may involve the use of similar ingredients including heavy metals like mercury for purported medicinal value [13]. Finally, certain religions like the Santeria (Cuban-based), Voodoo (Haitianbased), Palo Mayombe (Caribbean-based), and Espiritismo (Puerto Rican-based) use elemental mercury in religious and cultural ceremonies, since mercury was considered to be the element of the Gods and could be used to convert other metals into gold. It may be heated to form vapors that are inhaled, or sold as liquid beads and capsules that are made into decorative jewelry.

What is Known about the History of Mercury-Containing Products in Medicine and Health?

Mercury is used worldwide for a variety of medical conditions and, for centuries, was used in Western and Eastern civilizations as a medicinal remedy. Syphilis was common in the eighteenth century and administration of mercuric sulfide, or cinnabar ore, an inorganic mercurial compound, was reportedly effective. Cinnabar required both oral dosing and skin application, and is believed to have behaved like a primitive antibacterial chemotherapy [14]. These skin applications and the establishment of homeopathy in the eighteenth century, led to a practice of grinding compounds into a fine paste to enhance their clinical effectiveness. In some homeopathic rituals, mercuric paste is still used today in the treatment of syphilis. The use of mercury-containing laxatives for the treatment of constipation and preparations containing mercurous chloride (calomel) for the treatment of ascariasis are also well documented [15].

Mercury-containing dental amalgams is a large source of exposure to elemental mercury in the general population. Dental amalgam is a widely used restorative material that was introduced over 150 years ago. Mercury is bound within the amalgam and small amounts of mercury vapor are released from these fillings while chewing. The vapor is then absorbed through oral mucous membranes and undergoes oxidation in the oral cavity to inorganic mercury before entering the systemic circulation. Dentists used amalgams in tooth fillings that have historically contained up to $50 \%$ elemental mercury. Although the debate about the safety of mercury-containing dental amalgams continues, they are still used today. Use of dental amalgams is regulated by the Food and Drug Administration (FDA), and in 2008 the FDA reviewed the best available scientific evidence to determine whether the low concentrations of mercury vapor associated with dental amalgam fillings and mastication are a cause for concern. Based on this evidence, the FDA considers dental amalgam fillings safe for adults and children ages 6 and above. In addition, the amount of mercury vapor released in chewing is typically not enough to exceed the World Health Organization's (WHO) acceptable daily intake for total mercury [16]. Finally, the Center for Disease Control (CDC) does not consider the amount of mercury in these amalgams to be large enough to pose a significant health risk [17].

Thimerosal, or sodium ethyl mercurithiosalicylate, is an organic mercury compound that is approximately $50 \%$ elemental mercury by weight. Thimerosal was used extensively as an antibacterial agent and as a preservative in contact lens solutions and other topical and injectable biologic products. Thimerosal has also been used as a preservative in many vaccines since the 1930s, and it degrades into ethyl mercury and thiosalicylate in the tissues [18]. Controversy surrounding thimerosal-containing vaccines began in the 1950s after several outbreaks occurred resulting in maternal and fetal exposure to methylmercury $[19,20]$. Since methylmercury is a known neurotoxin, these exposures were causally linked to severe and progressive neurological impairments, such as cerebral palsy, observed in infancy and early childhood in the late 1990s [21]. Although these neurological phenomenon occurred after exposure to methylmercury, no such neurological impairments had yet to be linked with exposure to thimerosal, a derivative 
of ethylmercury, and the mercury contained in routinely administered vaccinations.

Historically, vaccine vials containing more than one dose may have been contaminated with pathogens after repeatedly puncturing the vial for multiple uses. As tragic cases of sepsis occurred in children in the late 1920s, the US Code of Federal Regulations responded to these cases in 1968 by mandating the use of preservative in vaccine vials that contained multiple doses or multidose vials. The Environmental Protective Agency (EPA) and FDA investigated these cases further and in 1999 determined that infants less than 6 months of age who received routinely recommended vaccinations in the USA would be exposed to amounts of "mercury" exceeding established safety levels [22]. These conclusions, however, were based on established exposure safety levels that previously existed for methylmercury and not the ethylmercury found in thimerosal-containing vaccinations [23]. Moreover, these levels of methylmercury had been previously established in collaboration by the FDA, Agency for Toxic Substances and Disease Registry (ATSDR), and WHO and ranged from 0.1 to $0.47 \mu \mathrm{g} / \mathrm{kg} /$ day [24]. Several factors contributed to this range of exposure levels, although levels from all three federal agencies were within the same order of magnitude. However, in 2000, the Congress requested the National Academy of Sciences to establish one accurate reference level and it was determined that $0.1 \mu \mathrm{g} / \mathrm{kg} / \mathrm{day}$ is a scientifically justified level of methylmercury exposure. The EPA and FDA subsequently reviewed all available data and ultimately concluded the maximum cumulative exposure to ethylmercury from vaccines in the recommended childhood immunization schedule was within acceptable limits for the protection of human health [25].

The American Academy of Pediatrics and the United States Public Health Service also responded to the associations of methylmercury exposure and neurocognitive impairments in reports published in 1999 by suggesting that thimerosal-containing vaccines be eliminated or removed whenever possible, although a causal link to autism has never been supported with scientific literature [26-28]. In addition, further investigations from federal agencies occurred to quantify the amount of ethylmercury found in standard vaccines and determine the exposure level of ethylmercury in some infants. In 1999, routinely recommended dosing guidelines of immunizations were weightbased and vaccinations received by infants less than 6 months of age in the USA contained $25 \mu \mathrm{g}$ mercury per $0.5 \mathrm{~mL}$ dose with infants less than 3 years of age requiring only half a dose (12.5 $\mu \mathrm{g}$ of mercury). Therefore, the amount of thimerosal contained in a single-dose vial $(0.5 \mathrm{~mL})$ of vaccine was not thought to be concerning. Rather, the more concerning sources of exposure to ethylmercury were multidose vials that required repeat punctur- ing and often used for heavier infants, or those infants requiring cumulative doses over the first 6 months of life. Based on these recommendations, by 2002, virtually all vaccines in the USA were converted to single-use vial formulations.

In addition, a study published by the CDC in 2007 showed that prenatal and infant exposure to vaccines and immunoglobulins that contain thimerosal does not increase the risk for autism spectrum disorders [29]. Finally, with the exception of some influenza vaccines, the use of thimerosal as a preservative in routinely recommended vaccines has been virtually eliminated in the USA since 2001 and is no longer considered a likely source of mercury exposure.

\section{Case Continuation}

The patient's second visit to our toxicology clinic occurred 4 weeks after her initial visit and 8 weeks following the exposure. At this time, she described that while her energy level and appetite had improved, they had not returned to her baseline. In addition, she reported mild pain in the gums and mild abdominal discomfort. She had no respiratory complaints or symptoms of a peripheral neuropathy such as extremity numbness or tingling. Her physical examination was unremarkable with the exception of one silver-colored tooth filling noted in the posterior oral cavity. Her laboratory tests at this visit showed that the mercury concentration in total blood had decreased to $32 \mu \mathrm{g} / \mathrm{L}$ (normal, $\leq 10 \mu \mathrm{g} / \mathrm{L}$ ) and a random spot urine mercury collection detected a concentration of $97 \mu \mathrm{g} / \mathrm{g}$ creatinine (normal, $0-10 \mu \mathrm{g} / \mathrm{g}$ creatinine). She underwent a second round of chelation therapy with oral DMSA for 20 days due to persistent symptoms.

\section{In Addition to CAM Products Used in This Case, What Are Other Potential Sources of Mercury Exposure in This Patient?}

Other common sources of mercury exposure include fish consumption and other environmental exposures. Diets high in fish, shellfish, or marine mammals (whales, seals, dolphins, and walruses) that come from mercurycontaminated waters are common sources of exposure to high amounts of organic mercury. Plankton and other microbial marine organisms convert elemental mercury in the ocean sediment to methylmercury, which bioaccumulates up the food chain leading to higher concentrations of mercury in larger predatory fish. These fish include saltwater fish such as shark and swordfish and freshwater fish such as pike and bass [30]. Consumption of contaminated fish is the major source of exposure to organic mercury in the US population [31]. FDA estimates that an average adult is exposed to about $3.5 \mu \mathrm{g}$ of mercury per 
day based on food consumption practices. Adverse health effects can be seen in vulnerable populations including children, pregnant women, and those consuming large quantities of fish [32]. Epidemiological studies examining the adverse effects of mercury exposure in prenatal groups have been controversial and do not conclude that the placental or in utero risks of mercury consumption outweigh the benefits of fish consumption. The 2004 FDA/EPA Joint Federal Advisory for fish consumption contained three recommendations for women who may become pregnant, pregnant women, nursing mothers, and the parents of young children. They stated that by adhering to these guidelines, women and young children would receive the benefits of eating fish and shellfish while reducing the exposure to harmful effects of mercury. The recommendations were as follows: (1) Do not eat shark, swordfish, king mackerel, or tilefish because they contain high levels of mercury. (2) Eat up to $12 \mathrm{oz}$ (two average meals) a week of a variety of fish and shellfish that are lower in mercury. These included five of the most commonly eaten fish that are low in mercury including shrimp, canned light tuna, salmon, pollock, and catfish. Another commonly eaten fish, albacore ("white") tuna has more mercury than canned light tuna. Therefore, a person can eat up to $6 \mathrm{oz}$ (one average meal) of albacore tuna per week. (3) Check local advisories about the safety of fish caught by family and friends in your local lakes, rivers, and coastal areas. If no advice is available, eat up to $6 \mathrm{oz}$ (one average meal) per week of fish you catch from local waters, but do not consume any other fish during that week.

Advisories on fish and wildlife consumption have been issued by states, Native Indian Tribes, and US territories regarding the consumption of fish and wildlife contaminated with methylmercury. These advisories make recommendations regarding quantity, type, and size of fish that are of concern. As of 2008, 50 states, 1 US territory, and 3 tribes have issued mercury advisories. Eighty percent of all advisories in 2008 were issued, at least in part, because of mercury [33]. In addition to fish and marine life, the US FDA conducted a total diet study from April 1982 to 1984 on selected industrial chemicals found in common foods purchased in retail stores. Table wine, beer, soft drinks, and various juices were also reported to contain trace levels of mercury which were at or below a designated detection limit [34].

Elemental mercury occurs naturally in the environment and low amounts are found in the air and water. These values are more than 2 orders of magnitude smaller than threshold levels currently considered to be "safe" to breathe. Elemental mercury is an odorless vapor; therefore, exposed persons may inadvertently remain in hazardous areas for several hours after toxic levels have been formed. Elemental mercury vapor is denser than air and can accumulate in low-lying areas, making children and persons living in poorly-ventilated areas more susceptible to its toxic effects [35]. The shorter height of a child may lead to inhalation of air closer to the ground and their larger body surface area to weight ratio when compared to adults, can lead to greater dermal absorption. Finally, vaporized mercury can remain on clothing, furniture, walls, and carpet for extended periods of time and continue to expose persons who come in contact with these household items [36].

Heavy metals like lead, cadmium, and mercury are natural constituents of air, water, and soil and are produced by numerous industrial processes making them a large source of contamination. However, amounts found in urban outdoor air and surface water are generally more than 2 orders of magnitude smaller than the threshold considered being "safe." Federal agencies like the EPA identify the most serious hazardous waste sites in the USA and include them in a list known as the National Priorities List. Elemental mercury has been currently identified in approximately $50 \%$ of these sites [37]. While our patient had no exposure or physical proximity to an industrial plant or hazardous waste site, it is extremely important to ascertain this information when evaluating patients that have heavy metal toxicity.

After Exposure and Systemic Absorption, How is Mercury Eliminated and What Are the "Classical" Clinical Manifestations of Mercury toxicity?

Elimination kinetics is dependent on the type of mercury present in the body. Elemental and inorganic mercury are eliminated mainly by the urine and feces, whereas elemental mercury elimination occurs in the urine via distal renal tubular secretion, exfoliation of tubular cells, and glomerular filtration. Mesenteric vessels of the GI mucosa allow transfer of inorganic mercury into the feces. In addition, inorganic mercury can be converted to elemental mercury in small amounts through reductase and dismutase enzymes, and eliminated through the skin and expired air [38]. Organic mercury is primarily excreted through the bile and feces. Enterohepatic recirculation accounts for its slightly longer half-life of 70 days, compared to the other forms of mercury which have a half-life of 30-60 days. Compounds like methylmercury are bound to reduced glutathione and degraded to cysteine complexes in the hepatocyte. These complexes are then reabsorbed by the intestines through enterohepatic circulation [39].

Clinical effects of mercury exposure involve virtually all organ systems, although these effects differ somewhat based on the three forms of mercury present. Elemental mercury toxicity predominantly affects the respiratory, renal, and neurological organ systems. Respiratory symp- 
toms following acute inhalational exposures to elemental mercury vapor include a constellation of findings such as cough, chills, and shortness of breath. These symptoms may resolve quickly or be prolonged and lead to more severe complications such as pneumonitis, pulmonary edema, and restrictive lung disease. Delayed-onset pulmonary fibrosis can occur even years following exposure [40]. Direct toxic effects to the alveolar epithelium from high concentrations of inhaled elemental mercury vapor can result in interstitial edema and hemorrhage while indirect effects involve binding of mercury to sulfhydryl groups of enzymes and proteins. Radiographic imaging following acute inhalational exposures have shown diffuse infiltrates [41]. Pulmonary function tests can display a wide spectrum of findings including obstruction, restriction, hyperinflation, and decreased vital capacity [42].

The kidney is very sensitive to the effects of elemental mercury and severe toxicity can result after inhalation exposure. Effects include manifestations of proteinuria, oliguria, and hematuria tubules [42, 43]. Exposure to elemental mercury stimulates the production of metallothionein, a metal-binding protein synthesized in the kidney and liver. This increased production of metallothionein may explain the increase in mercuric cations binding in the renal tubular cells, thus facilitating its elimination and shunting the metal away from other organs [1]. Damage can range from acute renal failure and necrosis of the proximal convoluted tubule $[1,43]$.

The predisposition of mercury ions to selectively target various regions of the brain such as the cerebral and cerebellar cortices after systemic absorption is known, but not well understood [44]. Neurological damage can occur after shortand long-term low-level exposure and can lead to findings including intention tremor, emotional lability, insomnia, and memory loss. Headaches, neuromuscular changes, and polyneuropathies including muscle atrophy and twitching have also been reported [45]. Tremors associated with elemental mercury toxicity characteristically affect the hands, are abolished during sleep, and are usually not debilitating. Neurasthenia is a complex of symptoms including fatigue, depression, headache, and loss of concentration, while erethism includes excessive shyness, anxiety, and increased irritability [46]. The fetus is particularly susceptible to elemental and organic mercury transmission resulting in severe renal and neurological toxicity [47].

Multiple other systemic manifestations can occur to varying degrees, including gingivostomatitis and immune thrombocytopenia. The former is a common finding after acute inhalational toxicity, whereas the latter phenomenon occurs in rare circumstances [48]. Deaths due to mercury vapor have been reported at serum and urine concentrations well below the amounts found in our patient; however, a longer duration of exposure at higher air concentrations and the severity of these patients' pulmonary injury may have been factors contributing to their death [49].

The clinical presentation of mercury toxicity from inorganic sources includes renal dysfunction, GI symptoms, and neurological abnormalities. Manifestations of renal dysfunction are similar to those seen after elemental mercury exposure and range from asymptomatic or transient proteinuria to the nephrotic syndrome with edema and hypo-proteinemia [50]. Neurological symptoms including benign hand tremors, drooling, and diplopia and signs including hyperactive deep tendon reflexes and lifethreatening seizures have been reported after a lethal dose of oral mercuric chloride [51]. While inorganic mercury salts are less lipophilic than elemental or organic forms and may not cross the BBB as readily, the slow elimination over 30-60 days may lead to prolonged exposure of neural cells to inorganic ions [52].

Approximately $90 \%$ of organic mercury is absorbed after an oral dose [53]. It is highly lipophilic, facilitating its penetration through the BBB. CNS effects can be severe and are thought to occur as a result of mercury accumulation within neurons. In summary, organic mercury is neurotoxic to humans and experimental animals and the major effects that are seen include motor disturbances, such as ataxia and tremors, as well as signs of sensory dysfunction, such as impaired vision. The predominant neuropathological feature is degenerative changes in the cerebellum. Finally, disruption of higher cognitive function has also been seen, as evidenced by depression and irritability [54].

How is the Diagnosis of Mercury Toxicity is Established? Are There Any Caveats to Consider When Using Laboratory Testing?

The presence of neuropsychiatric symptoms that are otherwise unexplained in the setting of abnormal kidney function should raise suspicion of mercury toxicity. While these symptoms may be the most reliable indicator of mercury toxicity, the diagnosis of mercurialism can be challenging for even the most experienced clinicians. Studies of occupational workers exposed to inorganic mercury from a chemical plant suggest that patients may not seek assistance until severe and progressive symptoms have occurred, because routine blood tests performed during the stages of initial work-up may be normal [51]. In addition, a comprehensive neurological evaluation may require specialized tests including nerve conduction studies and neuropsychiatric testing. These tests generally require additional time and will likely delay a correct diagnosis [51]. If mercury toxicity is suspected, specific questions regarding occupational exposures, diet (especially seafood consumption habits), ritualistic practices, and access to 
mercury-containing products should be asked. Overall, while the presence of mercury in biological samples may be helpful and used to confirm a diagnosis, there are currently no tests that are considered a criterion standard by which to diagnose mercury toxicity [55]. In addition, urinary mercury concentrations can be used to confirm exposure but do not correlate with severity of symptoms and poisoning. This was demonstrated in the 1950s after children were exposed to calomel (topically applied cream containing mercurous chloride) for treatment of teething or ascariasis. Children later developed a condition known as acrodynia despite minimally elevated urinary mercury concentrations that were only slightly elevated. Acrodynia, or pink disease, is characterized by a wide variety of clinical manifestations including a pink maculopapular skin rash, excessive sweating, hypertension, and tachycardia [56].

What Are the Appropriate Laboratory Tests to Consider Ordering in Cases of Mercury Toxicity?

Several laboratory tests are available to measure mercury concentrations, including whole blood concentrations (organic plus inorganic), urinalysis (inorganic), and hair sampling. Nail sampling is occasionally used in forensic investigations, but is otherwise considered unreliable. Whole blood concentrations are the most reliable indicator of total body burden after exposure to organic mercury. This method is able to detect the mercury concentration within the red blood cell where mercury is likely to accumulate based on its lipophilicity [47]. Studies evaluating acute exposures to elemental and inorganic mercury from a thermometer-manufacturing plant suggest that whole blood sampling is most accurate when collected in a trace element tube. However, as further distribution to tissues occurs, these values become less useful in correlating with total body burden [57].

Urine mercury concentrations are best utilized to confirm exposure and monitor the effectiveness of chelation therapy following exposure to inorganic mercury. Twenty-four-hour urine collections are more accurate than spot analysis concentrations, because of biologic variations that may exist in creatinine clearance and the likelihood that a spot urinalysis does not adequately represent glomerular filtration rates. While studies involving occupational workers exposed to long-term inorganic mercury from a chemical plant show that exposure is reflected in blood and urine, the specific time frame following exposure at which measurements become less reliable has not been determined [51]. In addition, although urine mercury concentrations may correlate with the severity of exposure and a patient's neuropsychiatric symptoms, these concentrations may also reflect the mercury content within the kidney and not necessarily serum, plasma, or total body burden [51].
Finally, hair analysis for mercury content and its correlation with serum and tissue concentrations has been an area of controversy for years. While it may be used in some aspects of forensic analysis, hair sampling is more of an indicator of long-term exposure to organic mercury [58]. Mercury found in the environment can bind to hair avidly; therefore, contamination of hair by mercury from environmental sources substantially decreases the reliability of hair testing as a measure of total body burden [59]. Dietary practices like fish consumption may also affect concentrations of mercury, particularly methylmercury, in hair samples as shown in the 1999-2000 data from National Health and Nutrition Examination Survey [60]. The results of this survey provided population-based data on hair mercury concentrations for women and children in the USA and showed that values were associated with age and frequency of fish consumption. Studies in occupational dental workers have shown that toenail mercury concentrations were lower than amounts obtained from fingernails and scalp hair and may be due to the fact that toenails are relatively free from external contamination except in barefoot people [61-63]. Compositional differences in hair and nail sulfur content and a relatively poor supply of blood flow to nails as reflected in their slow growth rate compared to hair may also be contributing factors for different levels of mercury in these samples [64]. Overall, while hair and nail analysis may be utilized in some circumstances, there is a lack of sufficient data supporting their use in estimating total mercury concentrations following exposure. In conclusion, current recommendations for the diagnostic evaluation of patients with mercury toxicity do not include hair or nail sampling.

What Are the Various Methods of Potential Treatment, Including Chelation, That Can Be Used in the Management of Mercury Toxicity?

The most urgent intervention in the management of acute mercury toxicity involves elimination of the exposure in relevant circumstances. After that is obtained there are a number of experimental therapies such as $N$-acetylcysteine (NAC), alpha tocopherol (vitamin E) and $N, N^{\prime}$-diphenyl-pphenylenediamine $\left(N, N^{\prime}\right.$-DPPD) and corticosteroids that will be discussed first. Animal studies have investigated the use of NAC for organic and inorganic mercury poisoning [65]. Results of these studies suggested that urinary excretion rates of mercury were higher for rats intoxicated with organic mercury compared with inorganic after NAC administration. While most forms of elimination like hemodialysis (HD) are virtually ineffective in mercury toxicity due to high protein binding and distribution of mercury to the CNS, one case report from 1984 suggested that a patient may have had enhanced urinary excretion of 
organic mercury following HD, 2,3-2,3-dimercapto-1-propanesulfonic acid (DMPS) and NAC [66]. Other antioxidants isolated from vegetable and plant oils have been used with some protective effects in rats including vitamin $\mathrm{E}$ and $N, N^{\prime}$-DPPD. These anti-oxidants are currently being used in industries to stabilize rubber and petroleum [67]. Finally, corticosteroids have been used in the case of mercury-induced interstitial granulomatous nephritis, but there are no controlled trials suggesting efficacy. In a single case report of corticosteroid use for inhaled mercury vapor toxicity, it was not clear if the corticosteroid had any effect on the outcome [68]. At this time, the available evidence above does not support the use of NAC, vitamin E derivatives, HD, or corticosteroids.

Chelation remains the most commonly encountered treatment for most forms of mercury toxicity. Chelation is the process of administering an agent that reduces the total body burden of a heavy metal with the ultimate goal of eliminating the chelator-metal complex from the body. Chelating agents contain thiol groups which are thought to compete with endogenous sulfhydryl groups for binding of mercury. Chelation therapy has historically been used to manage patients with severe symptoms and highly elevated circulating heavy metal concentrations. The ability of chelating agents to bind inorganic mercury and increase its elimination in the urine is well established, although randomized controlled trials that demonstrate changes in clinical outcome have not been performed [69]. In fact, a study performed in children with asymptomatic lead poisoning discovered that chelating with DMSA did not alter the neurodevelopmental effects of lead as assessed years following the exposure [70]. Other factors that complicate the use of chelation include an absence of consensus guidelines regarding which concentrations in various biological specimens require treatment; current recommendations are often based on clinical judgment and anecdotal data. For example, chronic exposure to mercury vapor with whole blood concentrations as low as $35 \mu \mathrm{g} / \mathrm{L}$ and urine levels of $150 \mu \mathrm{g} / \mathrm{L}$ may be an incidental finding during routine occupational worker testing, and associated with nonspecific symptoms [71]. Finally, patient compliance with chelation therapy is especially important for improving symptomatic control as well as preventing longterm sequelae of mercury toxicity including peripheral neuropathy, dementia, and memory impairment. Nevertheless, most toxicologists agree that chelation has a viable role in the treatment of mercury poisoning. Various chelating agents can be used for mercury toxicity (Table 1) and the side effects of such therapies depend on the agent being used as well as the route of administration. British Anti-Lewisite (BAL), DMSA, DMPS, and penicillamine are the most commonly used chelating agents used to treat various forms of mercury toxicity and will be briefly discussed.
BAL is only available in intra-muscular (IM) form and is most effective in the treatment of inorganic mercuric toxicity as the severe GI effects from toxic ingestions can limit the use of other chelating agents given in oral form [71]. BAL is not indicated following exposure to elemental mercury, because animal models have shown elevated brain levels of this form of mercury secondary to redistribution following BAL administration [72]. Side effects related to BAL therapy are dose-dependent and GI symptoms like nausea and vomiting are reported to be extremely common with other side effects such as rhinorrhea, salivation, fever, tachycardia and hypertension less common but potentially life-threatening. Reports of hypertensive encephalopathy with subsequent coma have occurred after a dose of $25 \mathrm{mg} / \mathrm{kg}$ in a pediatric case of arsenic ingestion [73].

Succimer is an orally administered metal chelator that has been anecdotally used to treat poisoning from all three forms of mercury. Succimer is available as a $100 \mathrm{mg}$ beadfilled capsule that can be ingested in whole or can be separated prior to use and sprinkled over food or taken with a drink. Overall adverse effects are mild but include GI symptoms such as nausea, vomiting, flatus, and diarrhea. A metallic taste has been reported for $10-20 \%$ of patients and mild elevations in hepatocellular enzymes including AST and ALT may occur and typically return to the patient's baseline after therapy is discontinued [74]. Finally, the adverse effect of leukopenia is observed rarely, but may warrant discontinuation of therapy depending on the severity. Succimer is advantageous over other chelating agents based on its oral administration and a mild toxic side effect profile. It has limited effects on the chelation of other trace metals like zinc, a common side effect of other chelating agents, which can result in zinc deficiency. One open-label study from 2000 showed that use of succimer in pediatric patients with lead toxicity demonstrated enhanced urine elimination [75]. However, a limited number of case reports in humans and a small number of animal studies all suggest that the use of succimer in mercury toxicity is most effective with the inorganic form [41]. For this reason, succimer is currently approved in cases of lead toxicity and is not currently FDA approved for mercury poisoning. Therefore, informed consent from our patient was obtained prior to initiating therapy. DMPS is currently an investigational drug in the USA (though with limited availability) and is available in oral and parenteral forms in some parts of the world. Rash, nausea, and leukopenia are rare side effects, but can be observed following its administration. Further research is needed to determine its overall efficacy and possible advantage over succimer.

Finally, D-penicillamine is a monothiol and available in oral preparation. Severe side effects are uncommon but can be observed in therapeutic doses and include GI distress, rashes, leukopenia, thrombocytopenia, and proteinuria. $\mathrm{N}-$ 
Table 1 Chelating agents currently available in the management of mercury toxicity

\begin{tabular}{|c|c|c|c|c|c|}
\hline Chelating agent & Routes & Side Effects & Elimination & Dose & $\begin{array}{l}\text { Forms of } \\
\text { mercury }\end{array}$ \\
\hline $\begin{array}{l}\text { British anti-lewisite } \\
\text { (BAL) }\end{array}$ & IM & $\begin{array}{l}\text { CARDIO: dose-related hypertension } \\
\text { GI: nausea, vomiting, abdominal pain }\end{array}$ & $50 \%$ Renal & $\begin{array}{l}5 \mathrm{mg} / \mathrm{kg} / \text { dose } \mathrm{q} 4 \mathrm{~h} \mathrm{IM} \times \\
48 \mathrm{~h} \text {, then } \\
2.5 \mathrm{mg} / \mathrm{kg} \mathrm{q} 6 \times 48 \mathrm{~h} \text {, then }\end{array}$ & Inorganic \\
\hline Dimercaprol $^{\mathrm{a}}$ & & $\begin{array}{l}\text { HEME: hemolysis (w/G6PD def) } \\
\text { NEURO: paresthesias, redistribution of } \\
\text { organic mercury can occur in animals }\end{array}$ & $\begin{array}{l}50 \% \text { Bile } \\
\text { and Feces }\end{array}$ & $2.5 \mathrm{mg} / \mathrm{kg} \mathrm{q} 12 \mathrm{~h} \times 7$ days & \\
\hline $\begin{array}{l}\text { 2,3-Dimercaptosuccinic } \\
\text { acid (DMSA) }\end{array}$ & $\mathrm{PO}$ & $\begin{array}{l}\text { GI: nausea, vomiting, diarrhea, flatus, } \\
\text { elevated liver function tests (LFTs) }\end{array}$ & Renal & $10 \mathrm{mg} / \mathrm{kg} \mathrm{BID} \times 14$ days & Inorganic \\
\hline Succimer, Chemet ${ }^{\mathrm{a}}$ & & $\begin{array}{l}\text { HEENT: metallic taste } \\
\text { HEME: rare-reversible neutropenia }\end{array}$ & & $10 \mathrm{mg} / \mathrm{kg}$ TID $\times 5$ days, then & Organic \\
\hline \multirow[t]{2}{*}{$\begin{array}{l}\text { 2,3-Dimercaptopropane- } \\
\text { 1-sulfonate (DMPS) }\end{array}$} & $\mathrm{PO}$ & $\begin{array}{l}\text { DERM: rash } \\
\text { GI: nausea }\end{array}$ & Renal & $\begin{array}{l}250 \mathrm{mg} \text { IV q } 4 \mathrm{~h} \times 48 \mathrm{~h} \text {, then } \\
250 \mathrm{mg} \text { IV q } 6 \mathrm{~h} \times 48 \mathrm{~h} \text {, then }\end{array}$ & Elemental \\
\hline & & HEME: leukopenia & & $\begin{array}{l}250 \mathrm{mg} \text { IV q } 8 \mathrm{~h} \text {, then } \\
300 \mathrm{mg} \text { PO TID } \times 7 \text { weeks }\end{array}$ & Inorganic \\
\hline Penicillamine & $\mathrm{PO}$ & $\begin{array}{l}\text { Hypersensitivity reactions: rash, pruritus, } \\
\text { drug fever, hematuria, antinuclear } \\
\text { antibodies, and proteinuria } \\
\text { Thrombocytopenia, agranulocytosis }\end{array}$ & Renal & $\begin{array}{l}\text { Empty stomach at least } 1 \mathrm{~h} \\
\text { before or } 3 \mathrm{~h} \text { after meals }\end{array}$ & Elemental \\
\hline $\begin{array}{l}N \text {-acetyl-D,L- } \\
\text { penicillamine (NAP) }\end{array}$ & & $\begin{array}{l}\text { Hepatitis, pancreatitis } \\
\text { Anorexia, nausea, vomiting }\end{array}$ & & $\begin{array}{l}20-30 \mathrm{mg} / \mathrm{kg} / \text { day divided } \\
\text { into four doses }\end{array}$ & Inorganic \\
\hline
\end{tabular}

${ }^{\mathrm{a}}$ Brand name

acetyl- $d$, $L$-penicillamine (NAP), an analog of D-penicillamine, is thought to be a more effective chelator of mercury [76]. NAP was used in Iraq in late 1971 during one of the largest outbreaks of methylmercury poisoning in history. Ninety-five thousand tons of plant seed grain treated with an organic mercury fungicide was consumed by thousands of people. More than 400 persons died, but data collected on these victims did not suggest any conclusive evidence with regards to changes in clinical outcome with NAP therapy [77].

\section{Case Continuation}

Following the patient's second visit in our toxicology clinic and the second round of chelation therapy, our team discussed the management with her primary care provider and we continued to follow her clinical course via telephone for several weeks. She stated compliance with the chelation regimen with no major side effects and gradually reported an increasing amount of energy with improved mood to her baseline. A total blood mercury concentration collected almost 6 months following the exposure was $23.9 \mu \mathrm{g} / \mathrm{L}$. A 24-h urine sample would likely have measured mercury concentrations more accurately for response to chelation; however, the patient refused to comply. Although the patient was asymptomatic, final treatment with a third round of chelation was initiated with oral succimer based on clinical judgment. An analysis of the traditional remedy by a commercial laboratory revealed elemental mercury content of $18 \%$ by weight. This test was performed via mass spectroscopy which ultimately measured a molecular weight of elemental mercury per gram of substance. A final clinical evaluation was performed by telephone approximately 8 months following exposure. The patient stated her symptoms had resolved with no further complaints.

What Public Health Agencies Regulate Mercury Exposure from the Environment?

While several federal agencies and organizations collaborate to ensure the safety and health of the public, there are three main agencies and two main organizations within the US Department of Health and Human Services that are known to be involved with mercury and other heavy metals. The three main agencies that establish regulations regarding mercury exposure include the EPA, the Occupational Safety and Health Administration, and the FDA. The two main organizations that provide information and recommendations on mercury but do not enforce regulations include the National Institute of occupational Safety and Health and the ATSDR. While the regulations and recommendations of each agency and organization may have been developed using various models and differ slightly from one another, they serve as guidelines that healthcare providers may use to manage patients that have been exposed to toxic levels of heavy metals and further assist in clinical decision making regarding possible management options. 


\section{Conclusion}

CAM products may contain harmful levels of heavy metals including mercury. Medical toxicologists, primary care providers, and other healthcare practitioners should be aware of the potentially hazardous side effects and toxicity that may result from use of these products. There are no currently established universal guidelines for when to initiate chelation therapy based solely on symptoms or on laboratory testing results, especially in the chronic exposure setting. Patients that are started on chelating agents should be evaluated at regular intervals for side effects, compliance, and response to therapy using serial concentrations in whole blood and/or urine. Finally, other sources of mercury exist and should be assessed during the initial history with attempts to eliminate any ongoing exposures as much as possible.

Conflicts of Interest The authors have no potential conflicts of interest to disclose

\section{References}

1. Rowens B, Guerrero-Betancourt D, Gottlieb CA et al (1991) Respiratory failure and death following acute inhalation of mercury vapor: a clinical and histologic perspective. Chest 99(185):190

2. Hursh JB, Clarkson TW, Cherian MG et al (1976) Clearance of mercury (Hg-197, Hg-203) vapor inhaled by human subjects. Arch Environ Health 31(302):309

3. Clarkson TW, Magos L, Myers GJ (2003) The toxicology of mercury-current exposures and clinical manifestations. N Engl J Med 349(1731):1737

4. Kazantzis G, Schiller K, Asscher A (1962) Albuminuria and the nephrotic syndrome following exposure to mercury and its compounds. Q J Med 3(403):441

5. Hursh JB, Clarkson TW, Miles EF et al (1989) Percutaneous absorption of mercury vapor by man. Arch Environ Health 44 (120): 127

6. Magos L (1988) Mercury. In: Seiler HG, Sigel H (eds) Handbook on toxicity of inorganic compounds. Marcel Dekker, New York, pp 419-436

7. Gogtay NJ, Bhatt HA, Dalvi SS et al (2002) The use and safety of non-allopathic Indian medicines. Drug Saf 25(1005):1019

8. Saper RB, Kales SN, Paquin J et al (2004) Heavy metal content of ayurvedic herbal medicine products. JAMA 292(2868):2873

9. Saper RB, Phillips RS, Sehgal A et al (2008) Lead, mercury, and arsenic in US-and Indian-manufactured Ayurvedic medicines sold via the Internet. JAMA 300(915):923

10. Food and Drug Administration. In: Federal Register. 1979. http:// www.fda.gov/BiologicsBloodVaccines/SafetyAvailability/ VaccineSafety/UCM096228\#act. Accessed 9 Nov 2010.

11. Wadekar MP, Rode CV, Bendale YN et al (2005) Preparation and characterization of a copper based Indian traditional drug: tamra bhasma. J Pharm Biomed Anal 39(951):955

12. Shastri MK (1965) Antiquity and originality of Hindu medicine. J Indian Med Prof 12(5511):5512

13. Wahlberg A (2006) Bio-politics and the promotion of traditional herbal medicine in Vietnam. Health 10(123):147
14. Norn S, Permin H, Kruse E et al (2008) Mercury - a major agent in the history of medicine and alchemy. Dan Medicinhist Arbog 36(21):40

15. Chopra A, Doiphode VV (2002) Ayurvedic medicine. Core concept, therapeutic principles, and current relevance. Med Clin North Am 86:75-89

16. World Health Organization (1991) Inorganic mercury. In: Environmental Health Criteria 118. http://www.fda.gov/ BiologicsBloodVaccines/SafetyAvailability/VaccineSafety/ UCMO96228\#thi. Accessed 9 Nov 2010.

17. Nightingale SL (1993) From the Food and Drug Administration. JAMA 269:2491

18. Magos L, Brown AW, Sparrow S et al (1985) The comparative toxicology of ethyl- and methylmercury. Arch Toxicol 57 (260):267

19. Bakir F, Damlugi SF, Amin-Zaki L et al (1973) Methylmercury poisoning in Iraq. Science 181(230):241

20. Harada M (1995) Minamata disease: methylmercury poisoning in Japan caused by environmental pollution. Crit Rev Toxicol 25 (1):24

21. Grandjean P, Weihe P, White RF et al (1997) Cognitive deficit in 7 year old children with prenatal exposure to methylmercury. Neurotoxicol Teratol 6(417):428

22. Mahaffey KR, Rice $G$ et al (1997). An assessment of exposure to mercury in the United States. In: Mercury study report to Congress. U.S. Environmental Protections Agency. Document EPA-452/R097-006.

23. American Academy of Pediatrics, Committee on Infectious Diseases and Committee on Environmental Health (1999) Thimerosal in vaccines - an interim report to clinicians. Pediatrics 104:570-574

24. World Health Organization (1996) Trace elements and human nutrition and health. Geneva: World Health Organization:209

25. Verstraeten T, Davis RL, DeStefano F et al (2003) Safety of thimerosal-containing vaccines: a two-phased study of computerized health maintenance organization databases. Pediatrics 112 (1039): 1048

26. Center for Disease Control and Prevention (1999) Recommendations regarding the use of vaccines that contain thimerosal as a preservative. MMWR pp. 996-998

27. Stehr-Green P, Tull P, Stellfeld M et al (2003) Autism and thimerosal-containing vaccines: lack of consistent evidence for an association. Am J Prev Med 25(101):106

28. Hviid A, Stellfeld M, Wohlfahrt J et al (2003) Association between thimerosal-containing vaccine and autism. JAMA 290 (1763): 1766

29. Price CS, Thompson WW, Goodson B et al (2010) Prenatal and infant exposure to thimerosal from vaccines and immunoglobulins and risk of autism. Pediatrics 126(656):664

30. Bjornberg KA, Vahter M, Grawe KP et al (2005) Methyl mercury exposure in Swedish women with high fish consumption. Sci Total Environ 341(45):52

31. Bjornberg A, Hakanson L, Lundbergh K (1988) A theory on the mechanisms regulating the bioavailability of mercury in natural waters. Environ Pollut 49(53):61

32. Dovydaitis $T$ (2008) Fish consumption during pregnancy: an overview of the risks and benefits. J Midwifery Womens Health 53(325):330

33. Environmental Protection Agency (2008) Bioaccumulative contaminants. In: National Listing of Fish Advisories 2008 General Fact Sheet: 2008 National Listing. http://water.epa.gov/scitech/ swguidance/fishshellfish/fishadvisories/fs2008.cfm. Accessed 11 Nov 2010.

34. Pedersen GA, Mortensen GK, Larsen EH (1994) Beverages as a source of toxic trace element intake. Food Additives and Contaminants 11(351):363

35. Wendroff AP (1990) Domestic mercury pollution. Nature 347:623 
36. Johnson CL (2004) Mercury in the environment: sources, toxicities, and prevention of exposure. Pediatr Ann 33(437):442

37. Environmental Protection Agency (2007) Priority chemicals. In: Waste-hazardous waste-waste minimization. http://www.epa. gov/wastes/hazard/wastemin/priority.htm. Accessed 11 Nov 2010.

38. Lovejoy HB, Bell ZG Jr (1973) Mercury exposure evaluations and their correlation with urine mercury excretions: recommendations for medical evaluation of mercury exposed workers in the chloralkali industry. J Occup Med 15(964):966

39. Clarkson T, Small H, Norseth T (1973) Excretion and absorption of methylmercury after polythiol resin treatment. Arch Environ Health 26(173): 176

40. Lilis R, Miller A, Lerman Y (1985) Acute mercury poisoning with severe chronic pulmonary manifestations. Chest 88(306):309

41. Bluhm RE, Bobbitt RG, Welch LW (1992) Elemental mercury vapour toxicity, treatment, and prognosis after acute, intensive exposure in chloralkali plant workers: part I. History, neuropsychological findings and chelator effects. Hum Exp Toxicol 11 (201):210

42. Snodgrass W, Sullivan JB, Rumack BH (1981) Mercury poisoning from home gold ore processing: use of penicillamine and dimercaprol. JAMA 246:1929-1931

43. Campbell JS (1948) Acute mercurial poisoning by inhalation of metallic vapour in an infant. Can Med Assoc J 58(72):75

44. White RF, Feldman RG, Moss MB et al (1993) Magnetic resonance imaging (MRI), neurobehavioral testing, and toxic encephalopathy: two cases. Environ Res 61(117):123

45. Adams C, Ziegler D, Lin J (1983) Mercury intoxication simulating amyotrophic lateral sclerosis. JAMA 250(642):643

46. Kanluen S, Gottlieb CA (1991) A clinical pathologic study of four adult cases of acute mercury inhalation toxicity. Arch Pathol Lab Med 115(56):60

47. Yoshida M (2002) Placental to fetal transfer of mercury and fetotoxicity. Tohoku J Exp Med 196(79):88

48. Fuortes LJ, Weismann DN, Graeff ML et al (1995) Immune thrombocytopenia and elemental mercury poisoning. J Toxicol Clin Toxicol 33(449):455

49. Murphy MJ, Culliford EJ, Parsons V (1979) A case of poisoning with mercuric chloride. Resuscitation 7(35):44

50. Naleway C, Chou HN, Muller T et al (1991) On-site screening for urinary $\mathrm{Hg}$ concentrations and correlation with glomerular and renal tubular function. J Public Health Dent 51(12):17

51. Rosenman KD, Valciukas JA, Glickman L et al (1986) Sensitive indicators of inorganic mercury toxicity. Arch Environ Health 41 (208):215

52. Clarkson TW (1997) The toxicology of mercury. Crit Rev Clin Lab Sci 34(369):403

53. Nordberg GF, Metabolism SS (1972) Mercury in the environment: an epidemiological and toxicological appraisal. In: Vostal J (ed) Friberg L. CRC Press, Cleveland, pp 29-92

54. Dales LG (1972) The neurotoxicity of alkyl mercury compounds. Am J Med 53(219):232

55. Goyer RA, Clarkson TW (2001) In: Klaassen CD (ed) Casarett and Doull's toxicology: the basic science of poisons, 6th edn. McGraw-Hill, New York, pp 811-867

56. Warkany J, Hubbard DM (1951) Adverse mercurial reactions in the form of acrodynia and related conditions. Am J Dis Child 81 (335):373
57. Kershaw TG, Clarkson TW, Dhahir PH (1980) The relationship between blood levels and dose of methylmercury in man. Arch Environ Health 35(28):36

58. Zareba G, Cernichiari E, Goldsmith LA et al (2008) Validity of methyl mercury hair analysis: mercury monitoring in human scalp/nude mouse model. J Appl Toxicol 28(535):542

59. Young JS (2010) Mercury. In: Nelson LS, Lewin NA, Howland MA et al (eds) Goldfrank's toxicologic emergencies. McGrawHill, New York, pp 1299-1307

60. McDowell MA, Dillon CF, Osterloh J et al (2004) Hair mercury levels in U.S. children and women of childbearing age: reference range data from NHANES 1999-2000. Environ Health Perspect 112(1165):1171

61. Suzuki T, Hongo T, Yoshinaga J et al (1993) The hair-organ relationship in mercury concentration in contemporary Japanese. Arch Environ Health 48(221):229

62. Helsby CA (1976) Determination of mercury in finger nails and body hair. Anal Chim Acta 82(427):430

63. Sinclair PM, Turner PR, Johns RB (1980) Mercury levels in dental students and faculty measured by neutron activation analysis. J Prosthet Dent 43(581):585

64. Amin SR, Gupta BL (1972) Estimation of sulphur content in human hair and nail for use in fast neutron dosimetry. Health Phys 23(243):244

65. Ballatori N, Clarkson T (1982) Developmental changes in the biliary excretion of methylmercury and glutathione. Science 216(61):63

66. Lund ME, Banner W Jr, Clarkson TW et al (1984) Treatment of acute methylmercury ingestion by hemodialysis with $\mathrm{N}$-acetylcysteine (Mucomyst) infusion and 2,3-dimercaptopropane sulfonate. J Toxicol Clin Toxicol 22(31):49

67. Ganther HE (1980) Interactions of vitamin $E$ and selenium with mercury and silver. Acad Sci 355(212):226

68. Solis MT, Yuen E, Cortez PS et al (2000) Family poisoned by mercury vapor inhalation. Am J Emerg Med 18(599):602

69. Dietrich KN, Ware JH, Salganik M, Treatment of Lead-Exposed Children Clinical Trial Group et al (2004) Effect of chelation therapy on the neuropsychological and behavioral development of lead-exposed children after school entry. Pediatrics 114(19):26

70. Aposhian HV, Maiorino RM, Rivera M et al (1992) Human studies with the chelating agents, DMPS and DMSA. J Toxicol Clin Toxicol 30(505):528

71. Wang EE, Mahajan N, Wills B et al (2007) Successful treatment of potentially fatal heavy metal poisonings. J Emerg Med 32(289):94

72. Aposhian M, Maiorano R, Xu Z et al (1996) Sodium 2,3dimercapto-1-propanesulfonate (DMPS) treatment does not redistribute lead or mercury to the brain of rats. Toxicology 109(49):55

73. Longcope WT, Luetscher JA (1949) The use of BAL (British antiLewisite) in the treatment of the injurious effects of arsenic, mercury and other metallic poisons. Ann Intern Med 31(545):554

74. Liebelt E, Shannon M (1994) Oral chelators for childhood lead poisoning. Pediatr Ann 23(616):626

75. Chisolm JJ (2000) Safety and efficacy of meso-2,3-dimercaptosuccinic acid (succimer) in children with elevated blood lead concentrations. J Toxicol Clin Toxicol 38(365):375

76. Hryhorczuk DO, Meyers L Jr, Chen G (1982) Treatment of mercury intoxication in a dentist with $N$-acetyl-D,L-penicillamine. J Toxicol Clin Toxicol 19(401):408

77. Aposhian HV, Carter DE, Hoover TD et al (1984) DMSA, DMPS, and DMPA — as arsenic antidotes. Fundam Appl Toxicol 4:S58-S70 